\title{
SHOPPING EXPERIENCE AND SUBJECTIVE WELL-BEING: AN EMPIRICAL STUDY
}

\author{
Ananda Sabil Hussein \\ Faculty of Economics and Business, Universitas Brawijaya, Indonesia \\ (sabil@ub.ac.id)
}

\begin{abstract}
While a traditional marketer aims to enhance customer loyalty, a social marketer focuses on the creation of individual well-being. To date, some social marketing programs have been launched to enhance individual well-being. However, only a few studies have been oriented to investigate subjective well-being, in the domain of traditional marketing. Previous studies have indicated that service quality is an important determinant of subjective well-being for a service organization's customers. However, this notion is not enough as service quality only captures the performance of service in the level of the attribute. For that reason, this introduces the notion of experience quality as the determinant of subjective well-being. To have a better knowledge about the relationship between these constructs, this study also inserted the notion of customer satisfaction and perceived shopping enjoyment as mediating variables. Two hundred respondents participated in this study. These respondents were recruited at department stores in Malang, a city in the Province of East Java. A selfadministered survey was conducted to collect the data. A Covariance Based Structural Equation Model (CBSEM) was employed to analyze the data. The results of a Confirmatory Factor Analysis (CFA) confirmed the model proposed. The structural model showed that the experience of shopping has significant effects on customer satisfaction, perceived shopping enjoyment, and subjective wellbeing. However, this study failed to prove the mediating effects of customer satisfaction and perceived shopping enjoyment in the relationship between the shopping experience and subjective well-being. Upon the completion of this study, both theoretical and practical contributions were provided.
\end{abstract}

Keywords: shopping experience, perceived enjoyment, customer satisfaction, subjective well-being

JEL Classification: M.31 


\section{INTRODUCTION}

In the present day, creating individual well-being has been the concern of social marketers. Some studies have documented social marketing activities attempting to enhance well-being. For example the study by Hussein et al. (2014) of the social marketing campaign to promote six months of exclusive breastfeeding in Indonesia. Another social marketing study related to creating individual health and well-being was the study by Lowry et al. (2004) about pregnant women stopping smoking. While the literature explained that social marketing aims to create individual well-being, the study by $\mathrm{Su}$ et al. (2016) indicated that service quality, as an essential variable in commercial marketing, played an important role in creating well-being. This study explained that the quality perceived by Chinese tourists would affect both their intention to revisit and their subjective wellbeing.

The quality of the experience provided is one of the important constructs in marketing. Previous studies showed that experience quality had a significant effect on customers' loyalty. These studies indicated that customers tend to be more loyal when they perceive they had a better experience. The important role of the experience's quality is not only recognized in the area of marketing; studies into retail management also found that the quality of the experience affected both the customers' satisfaction and loyalty (Fullerton, 2005; Sirohi et al., 1998; Sivadas \& Baker-Prewitt, 2000). Apart from its effect on satisfaction and loyalty, scholars (Su et al., 2015; Su et al., 2016) explained that the experience quality played an important role in creating subjective well-being, particularly in the area of tourism studies.

While the notion of experience quality has been stated to have a significant effect on subjective well-being in the domain of tourism studies (Su et al., 2015; Su et al., 2016), there is a lack of any studies investigating the effect of the quality of the shopping experience on subjective well-being in the area of the retail industry.

In addition, these two previous studies did not clearly explain the process of how the quality of the experience affected subjective well-being. To fill these gaps, this study tested the direct effect of the shopping experience's quality on subjective well-being, and also inserted the notion of perceived enjoyment and customer satisfaction, to enhance the insight about how the process of the quality of the shopping experience affects subjective wellbeing.

The idea of perceived enjoyment is developed in this study to bridge the effect of the shopping experiences' quality on subjective well-being. Previous studies found that customers who enjoyed their shopping experience have a better quality of life than the customers who did not enjoy their shopping experience (Su et al., 2016). This means perceived enjoyment significantly affects subjective well-being. As the determinant of subjective well-being, perceived enjoyment was predicted to be the result of the shopping experience's quality, as many studies have empirically found the effect of an experience's quality on enjoyment (Hwang \& Kim, 2007; Kim et al., 2013).

Traditionally, customer satisfaction has been recognized as the predictor of customer loyalty (Hallowell, 1996; Wallin Andreassen \& Lindestad, 1998). These previous studies indicated that the more satisfied a customer is, the greater their loyalty will be. Apart from its direct, significant effect on loyalty, satisfaction, as a form of attitude, plays an important role in creating subjective well-being (Bergstad et al., 2011; Su et al., 2016). These studies indicated 
that the well-being of the customers tended to be greater for the satisfied customer than for the unsatisfied customer. Reflecting on the servicedominant logic theory: experience is a further form of service. Many studies have shown that service quality has a significant effect on customer satisfaction. Thus, as a derivation of service quality, the quality of the shopping experience is predicted to have a significant effect on customer satisfaction.

Based on the background, this study aims to:

1. Investigate the effect of the shopping experiences' quality on individuals' subjective well-being.

2. Determine the mediating effects of perceived enjoyment and customer satisfaction in the relationship between the shopping experience's quality and the individual's subjective well-being.

Upon the completion of this study, both theoretical and practical contributions are provided. From the theoretical standpoint, this study contributes by creating a comprehensive model consisting of the shopping experiences' quality, the customers' satisfaction and perceived enjoyment to create the individuals' subjective well-being. From a practical perspective, this study provides insights for a department store or retail shop managers in managing their departments.

\section{LITERATURE REVIEW}

\section{Shopping Experience Quality and Subjective Well-being}

The idea of the quality of an experience is derived from the notion of service quality. $\mathrm{Wu}$ and $\mathrm{Ai}$ (2016) suggested that customer experience is about the individual's response to the holistic direct and indirect contact with the service provider. Lemke et al. (2011) explained that experience quality is a perceived judgment about the excellence or superiority of the customer's experience. Hence, a shopping experience's quality is about the excellence perception of the shoppers, with regard to their direct and indirect contact with the department store's environment, including the shop assistants, the physical environment and valence.

In the realm of commercial marketing, some studies have shown the importance of experience quality on customer satisfaction and loyalty important variables in the customer relationship paradigm. For example, the study of Chen and Chen (2010) indicated that the quality of the experience felt by heritage tourists positively affected their intention to revisit the heritage tourism site. In the research of golf courses' experience quality, Wu and Ai (2016) found that the experience quality plays an important role in affecting the golfers' satisfaction and loyalty.

Apart from its important effect on both satisfaction and loyalty, the current studies showed that the quality of the experience has an important role in improving the quality of life or subjective well-being (Su et al., 2015; Su et al., 2016). In general, an individual's subjective well-being can be developed through the relaxation of the body and mind (Smith \& Puczkó, 2008). Thus, the better the quality of the experience perceived by the customers is, the better their subjective well-being will be.

Based on these contentions, there is a possibility that, in the area of the department store, the shopping experiences' quality would increase the individuals' subjective well-being.

H1: Shopping experience quality positively affects subjective well-being

\section{The Mediating Effect of Perceived Enjoyment}

The enjoyment perceived by a customer cannot be separated from their experience (Bauer et al., 2005). H.-Y. Wang (2012) explained that 
enjoyment is the feeling of pleasure, relaxation, and joy that customers gain from their encounter with a service provider. To experience this enjoyment, four dimensions need to be offered by service providers, namely: relaxation, happiness, enjoyment, and wonder ( $\mathrm{Wu}$ et al., 2016).

In the marketing realm, an individual's enjoyment is the result of a good quality experience. The study of Hwang and Kim (2007) showed that an individual's browsing experience quality affects their enjoyment of internet surfing. Kim et al. (2013) indicated that the quality of the system, and the information provided as part of a tourist's experience, significantly affect their enjoyment.

As an important construct in marketing, perceived enjoyment plays an important role in affecting the individual quality of life or subjective well-being. Individuals who enjoy their lives would have better well-being. Studies show that perceived enjoyment has a close relationship with happiness (Van der Heijden, 2004). In the area of shopping behavior, Y. J. Wang et al. (2010) explained that customers' enjoyment in retail shopping is closely related to their quality of life. As perceived enjoyment is the outcome of a shopping experience's quality, and also has a strong relationship with subjective well-being, potentially this construct might explain the effect of the quality of shopping experience on an individual's subjective wellbeing. Hence:

H2: Perceived enjoyment mediates the effect of a shopping experience's quality on subjective well-being.

\section{The Mediating Effect of Customer Satisfaction}

Customer satisfaction is about the gap between an individual's expectation and perception (Kotler \& Keller, 2012). Marketing studies show that customer satisfaction has an important role in an individual's subjective well-being. The greater the customer's satisfaction, the better the subjective well-being will be. For example, the study of Bergstad et al. (2011) indicated that the satisfaction of daily travel affects subjective well-being. Su et al. (2016) showed that tourists' satisfaction significantly affects tourists' subjective well-being.

Some variables have been recognized to be the predictors of customer satisfaction. The current studies show that a good experience, experienced by an individual, would affect their satisfaction. Theoretically, individuals who have better experiences would be more satisfied than those who do not have a good experience. Previous studies empirically proved that there is a positive and significant effect of an experience's quality on customers' satisfaction (Wu \& Cheng, 2013; Wu \& Ko, 2013).

As previous studies have indicated, customer satisfaction is the result of the quality of the experience; and it is the predictor of subjective well-being. There is a possibility that customer satisfaction mediates the effect of the shopping experience's quality for an individual's subjective well-being. Hence, this study proposes:

H3: Customer satisfaction mediates the effect of the shopping experience's quality on subjective well-being 


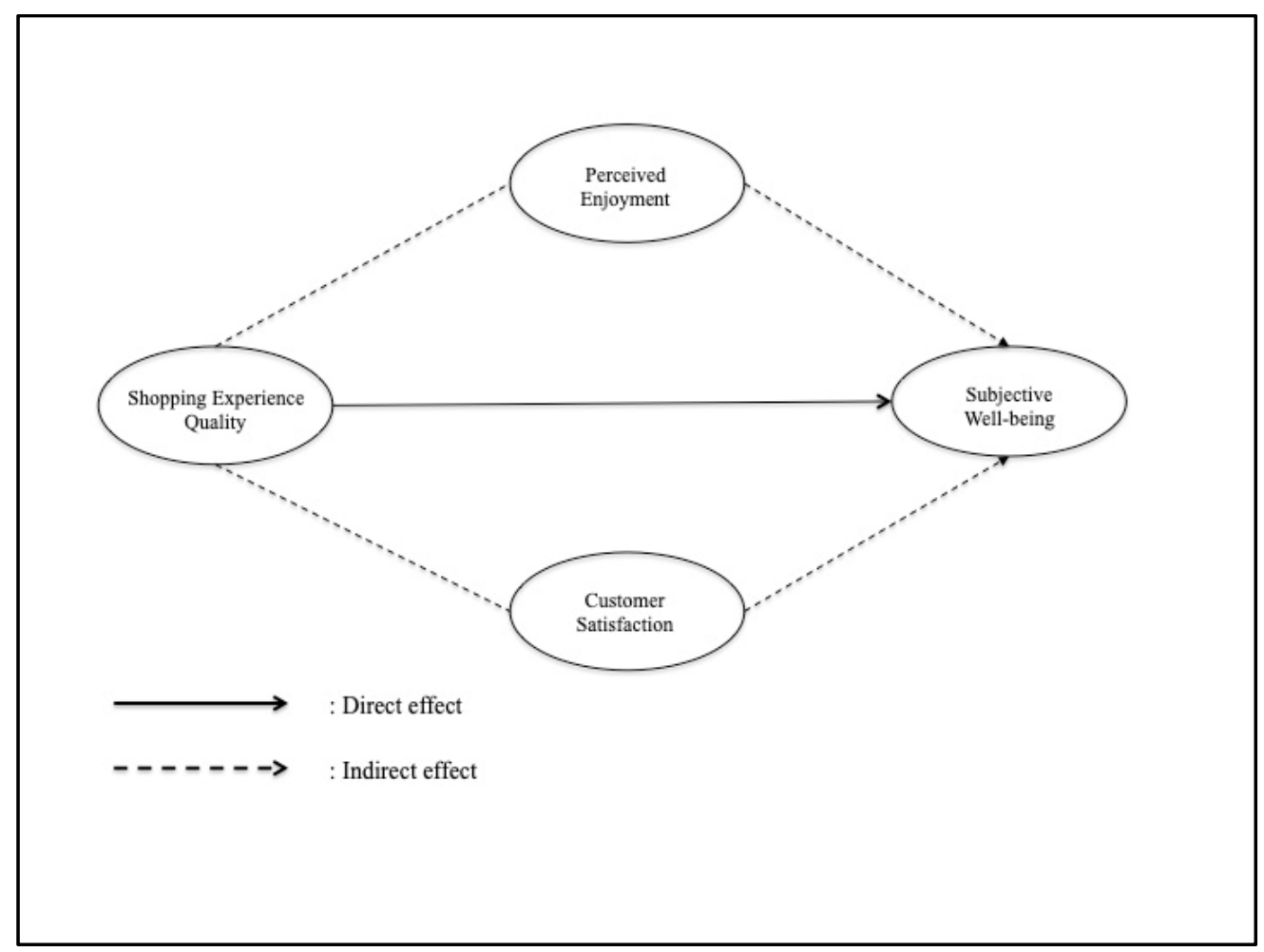

Figure 1. Research Model

\section{RESEARCH METHOD}

\section{Sample}

The respondents in this study were shoppers in various department stores in Malang, East Java, Indonesia. A total of 200 respondents participated in this study. The respondents were recruited through a purposive sampling method, with the sample's characteristics being that they are more than 17 years old, go shopping by their own choice, and have visited the department store at least twice. The following demographic data emerged from the sample: $60.5 \%$ of the respondents are female, $33.5 \%$ are aged between 21 - 30 years old, 37.5\% have a bachelor degree and $72.5 \%$ have an income between IDR. $1,000,000$ and 5,000,000 per month.

\section{Measurement}

A self-administered questionnaire was used in this study. Prior to collecting the data, the questionnaire to be used was tested for both its content and construct validities. For the content validity, two academics and a retail-shopping manager were requested to give their feedback. The construct's validity was tested by doing a pilot study with 30 respondents. Upon the completion of the pilot study, the results of the validity and reliability tests showed that there were no validity and reliability problems. Hence, the questionnaire could be used in this study.

The questionnaire is divided into two parts. The first part asks about the demographic profile of the respondent, and the second part was designed to ask about the constructs being tested. For this study, the measures used were adapted from several previous studies. A fivepoint Likert scale anchored from strongly disagrees (1) to strongly agree (5) was employed in this study. The construct of experience quality was adapted from Wu and Ai (2016). Perceived enjoyment was adapted from Wu et al. (2016). Customer satisfaction was adapted from Wilson et al. (2012), and subjective well-being was adapted from Su et al. (2016). 
Table 1. Demography of Respondents

\begin{tabular}{ccrr}
\hline Variable & Indicator & Percentage & Respondents \\
\hline Gender & Male & $39.5 \%$ & 79 \\
& Female & $60.5 \%$ & 121 \\
Age & $<21$ years old & $10.5 \%$ & 21 \\
& $21-30$ & $33.5 \%$ & 67 \\
& $31-40$ & $23 \%$ & 46 \\
& $41-50$ & $17 \%$ & 34 \\
Education & $>50$ & $16 \%$ & 32 \\
& High School & $17 \%$ & 34 \\
& Diploma & $28 \%$ & 56 \\
& Bachelor & $37.5 \%$ & 75 \\
Income & Postgraduate & $15 \%$ & 30 \\
& Doctoral & $2.5 \%$ & 5 \\
& $<1,000,000$ & $6 \%$ & 12 \\
& $1,000,001-5,000,000$ & $72.5 \%$ & 145 \\
& $5,000,001-10,000,000$ & $12 \%$ & 24 \\
& $>10,000,000$ & $9.5 \%$ & 19 \\
\hline
\end{tabular}

Source: Primary Data analyzed, 2018

\section{DATA ANALYSIS}

Structural Equation Modeling (SEM) with a maximum likelihood method was used in this study to answer the research objectives. In conducting the SEM, a two-step analysis was used. The first step was a Confirmatory Factor Analysis (CFA), to examine the fitness of the measurements used. In testing the model's fitness, three fit indexes were employed in this study. They are the absolutely fit indexes (Goodness of Fit/GFI), incremental fit indexes (Normed Fit Indexes/NFI and Comparative Fit Index/CFI) and parsimonious fit indexes (normed square and Parsimony Goodness of Fit Index/PGFI). According to Kline (2005), the cut-off value for GFI, NFI, and CFI is greater than 0.9 , normed square is less than 0.5 and PGFI is more than 0.5. Apart from the model's fitness, to ensure the robustness of the measurement used, this study also tested the score of the factor loading, the discriminant validity among the constructs, and the constructs' reliability. For the factor loading Hair et al. (2010) suggested that the minimum factor loading for CFA should be above 0.6. Discriminant validity is tested through investigating the correlation among the constructs. Hair et al. (2010) suggested that to have free discriminant validity, the correlation among the constructs must be less than 0.85 . In testing the reliability, this study used the constructs' reliability, which must have a score above 0.6 (Hair et al., 2014).

Upon the completion of CFA, the second step was a path analysis and mediating test analysis. In testing the proposed hypotheses, alpha was set at the level of 5\% $(t=1.960)$. Baron and Kenny’s mediation analysis approach (1986) was employed by this study. In accordance with this approach, a mediation effect occurs if a predictor has a significant effect on the mediator, and the mediator significantly affects the criterion. Upon the completion of the indirect estimation, Sobel's test was employed to estimate the $\mathrm{Z}$ score. Sobel's test was calculated through:

$$
\mathrm{Z}=a^{*} b / \sqrt{(b 2 * s a 2+a 2 * s b 2)}
$$




\section{RESULT AND DISCUSSION}

\section{Measurements}

Prior to testing the proposed hypotheses, CFA was conducted by this study. Following Kline's suggestion (2005), in running the CFA all the constructs used were assumed to covary each other. The initial CFA results indicated a poor model $(\mathrm{GFI}=0.861$; NFI $=0.895$; $\mathrm{CFI}=0.963$, normed square $=2.125$ and PGFI $=0.603)$. As the model is considered to be a poor fit, a further modification to the model was conducted. The model was modified by excluding item CS1 from the model. This resulted in a better model fitness (GFI $=0.913$; NFI $=0.933$; CFI $=0.928$, normed square $=2.925$ and PGFI $=0.592$ ) .

Apart from evaluating the model's fit index, its convergent validity, discriminant validity, and reliability were also tested in this study to confirm the fitness of the model. The CFA showed that the factor loading varied between 0.703 and 0.906 and the score of Average Variance Extracted (AVE) varied between 0.591 and 0.707 . These indicators showed that there is no convergent validity problem in the measurements used. Table 2 summarized the score of the factor loading, AVE and Composite Reliability (CR) for each item.

The discriminant validity was examined by investigating the correlation among the constructs. From the statistical analysis, the correlation among the constructs varied between 0.590 (the correlation between perceived enjoyment and subjective well-being) and 0.887 (the correlation between customer satisfaction and shopping experience). This finding showed that there was a lack of discriminant validity between customer satisfaction and shopping experience. However, an assessment of the content's validity, by a panel of experts, indicated that the indicators loaded on the separate constructs are distinct and nomologically valid (Hair et al., 2014). To ensure that the constructs tested are different, a multicollinearity test was performed. The result of this multicollinearity test explained that the Variance Inflation Factor (VIF) score varies between 2.232 and 2.651. Thus it can be

Table 2. Summary of Factor Loadings, AVEs and CRs

\begin{tabular}{ccccc}
\hline Construct & Item & Factor Loadings & AVE & $\begin{array}{c}\text { Composite } \\
\text { Reliability }\end{array}$ \\
\hline \multirow{3}{*}{ Shopping Experience } & SE1 & 0.853 & & 0.861 \\
& SE2 & 0.760 & 0.674 & \\
& SE3 & 0.848 & & 0.877 \\
& PE1 & 0.898 & & \\
Perceived Enjoyment & PE2 & 0.906 & 0.707 & \\
& PE3 & 0.703 & & \\
& CS2 & & & \\
Customer Satisfaction & CS3 & 0.766 & & \\
& CS4 & 0.895 & 0.687 & \\
& CS5 & 0.866 & & 0.811 \\
& SW1 & 0.783 & & \\
Subjective Well-being & SW2 & 0.853 & 0.591 & \\
& SW3 & 0.733 & & \\
\hline
\end{tabular}

Source : Primary Data analyzed, 2018 
concluded that the constructs tested are different. Reliability was measured through an analysis of the composite reliability score. For this study, the composite reliability ranged between 0.811 and 0.897 . This result means that there is no reliability problem in the study.

\section{Structural Model}

Hypothesis 1 proposed the direct effect of the shopping experience's quality on individuals' subjective well-being. The statistical estimation showed that there is a significant positive effect of shopping experience's quality on subjective well-being ( $\beta=0.791: p<0.05$ ) This finding means that the better the shopping experience is, as perceived by the department store's visitors, the higher their subjective well-being will be. This supports Hypothesis 1.
Hypothesis 2 proposed the mediating effect of perceived enjoyment. The statistical calculation indicated that there is no mediating effect of perceived enjoyment, as these constructs did not directly affect the subjective well-being, although perceived enjoyment was found to be the result of the shopping experience's quality. The statistical analysis showed that the indirect effect coefficient was 0.020 (0.843 x 0.024) and Sobel's test z-value indicated a score of 0.151 (see appendix for Sobel's test calculation), which was lower than the cut off value (1.960). This insignificant mediating effect means the quality of the shopping experience does not have an indirect effect on subjective well-being through shopping enjoyment.

Table 3. Correlation Among Constructs

\begin{tabular}{lcccc}
\hline & $\begin{array}{c}\text { Shopping } \\
\text { Experience }\end{array}$ & $\begin{array}{c}\text { Perceived } \\
\text { Enjoyment }\end{array}$ & $\begin{array}{c}\text { Customer } \\
\text { Satisfaction }\end{array}$ & $\begin{array}{c}\text { Subjective } \\
\text { Well-being }\end{array}$ \\
\hline Shopping Experience & 1 & & & \\
Perceived Enjoyment & 0.831 & 1 & & \\
Customer Satisfaction & 0.887 & 0.773 & 1 & 1 \\
Subjective Well-being & 0.690 & 0.590 & 0.594 & \\
\hline Source: Primary Data analyzed, 2018 & & &
\end{tabular}

Table 4. Summary of Hypotheses Testing

\begin{tabular}{clllll}
\hline Hypothesis & & \multicolumn{1}{c}{ Path } & \multicolumn{1}{c}{ Coefficient } & \multicolumn{1}{c}{ Critical Ratios } & \multicolumn{1}{c}{ Remarks } \\
\hline H1 & SEQ $\rightarrow$ SW & & 0.791 & 2.852 & Supported \\
H2 & Step 1 & SEQ $\rightarrow$ SW & 0.791 & 2.852 & Supported \\
& Step 2 & SEQ $\rightarrow$ PE & 0.843 & 9.507 & N/A \\
& Step 3 & PE $\rightarrow$ SW & 0.024 & 0.158 & N/A \\
& Step 4 & SEQ $\rightarrow$ PE $\rightarrow$ SW & $(0.843 \times 0.024) ~ 0.020$ & 0.151 & Not Supported \\
H3 & Step 1 & SEQ $\rightarrow$ SW & 0.791 & 2.852 & Supported \\
& Step 2 & SEQ $\rightarrow$ CS & 0.896 & 13.155 & N/A \\
& Step 3 & CS $\rightarrow$ SW & -0.133 & -0.628 & N/A \\
& Step 4 & SEQ $\rightarrow$ CS $\rightarrow$ SW & $(0.896 \times-0.133)-0.119$ & -0.608 & Not Supported \\
\hline
\end{tabular}

*significant at $\mathrm{p}<0.01$; **significant at $\mathrm{p}<0.001$

SEQ: Shopping Experience Quality; PE: Perceived Enjoyment; CS: Customer Satisfaction; SW: Subjective Well-being 
Hypothesis 3 predicted the mediating effect on customer satisfaction. However, the statistical estimation showed that the indirect coefficient was -0.119 (0.896 x -0.113) with a z-value of 0.608 (see appendix for Sobel's test calculation). It means there is no mediating effect provided by customer satisfaction. This insignificant effect of the mediating effect means Hypothesis 3 is not supported. Table 4 summarizes the results of the hypotheses tests.

Two research objectives were investigated in this study. The first research objective related to the direct effect of the quality of experience on individuals' subjective well-being. The second research objective was to test the mediating effect for both perceived enjoyment and customer satisfaction in the relationship between the shopping experience's quality and subjective well-being. The following section discusses the findings of this study.

The direct effect of shopping experiences' quality on subjective well-being was proposed in this study. The statistical estimation found that there is a positive, significant effect of shopping experiences' quality on subjective well-being. This finding means an individual's subjective well-being will be higher upon experiencing a better quality shopping experience. The positive, significant effect of a shopping experience's quality on subjective well-being strengthens the previous studies, by explaining that the better the experience's quality is, as perceived by the customers, the better the individual's subjective well-being will be (Su et al., 2015; Su et al., 2016).

Apart from testing the direct effect of shopping experiences' quality on subjective well-being, this study also tested the indirect effect of shopping experiences' quality on subjective well-being through perceived enjoyment and customer satisfaction. While some studies signaled an indirect effect of the experience's quality on subjective well-being through perceived enjoyment, this study did not

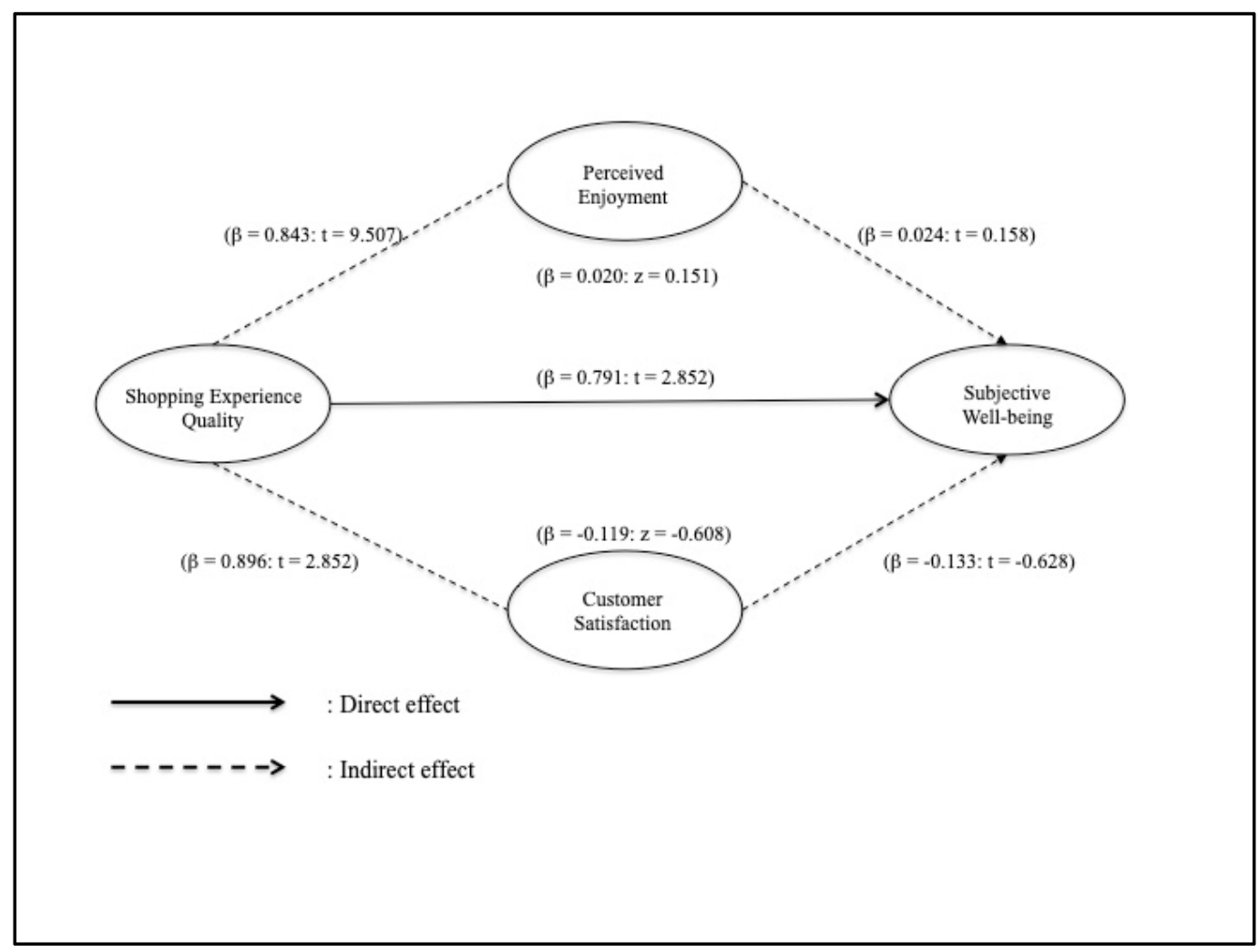

Figure 2. Structural Model 
find this indirect effect. The insignificant

indirect effect of shopping experiences' quality on subjective well-being through perceived enjoyment is in line with the suggestion of Y. J. Wang et al. (2010) regarding the customer's culture. Generally, this current study divides culture into two: masculine culture and feminine culture. In the masculine culture, ones' quality of life is defined by their social status and achievements, while feminine culture defines the quality of life based on freedom and flexibility. Indonesia holds eastern culture, which has a high degree of masculinity. It means that the quality of life is determined by their social status and achievements (Hofstede Insight, 2018). Thus, for Indonesians, enjoying shopping activities is not considered to be a way to increase subjective well-being. So the proposed hypothesis was rejected.

Customer satisfaction is the gap between a customer's expectation and perception (Parasuraman et al., 1985). While it was proposed as having a mediating effect between the shopping experiences' quality and subjective well-being, this study did not find its effect. This insignificant mediating effect of customer satisfaction is probably because satisfaction itself is not enough to enhance an individual's subjective well-being. There is a need for other variables to increase individuals' subjective well-being.

The Stimuli-Organism-Response (S-O-R) framework (Vieira, 2013) can be used to explain the insignificant mediating effect of both perceived enjoyment and customer satisfaction. According to this theory, an individual's behavior sequence consists of Stimulus Organism - Response (S-O-R). The S-O-R framework suggested that stimulus is a factor that affects the internal states of individuals, organism is an internal process, and structures mediate between the external stimuli and the individual's actions, response or final outcome; and response is a final outcome from an individual, represented by an approach or avoidance behavior (Chang et al., 2011).

Referring to this S-O-R framework, the constructs of perceived enjoyment and customer satisfaction are recognized as the organism elements, since these constructs are individual processes within the respondent's mind. Similar to satisfaction and enjoyment, they capture the well-being perceptions of the respondents, rather than the final behavior. Subjective well-being is considered to be an organism element. Based on these arguments, enjoyment, satisfaction and subjective well-being are considered as organism elements, since these three constructs are not the final outcomes of any behavior. As organism elements, they do not affect one another. Hence, both customer satisfaction and perceived enjoyment did not mediate the effect of the shopping experience on subjective well-being.

\section{CONCLUSION}

Upon completion of this study, a theoretical contribution was provided to the body of marketing literature, especially in the area of retail marketing. This study theoretically proves that shopping experiences' quality plays an important role in enhancing individuals' subjective well-being. This study noted that the shopping experience's quality does not need a mediator to affect the subjective well-being, as the analysis showed that both customer satisfaction and perceived enjoyment did not mediate the effect of shopping experiences' quality on subjective well-being.

From a practical standpoint, this study implies that department store managers must provide a good shopping experience, as the visitors who undergo a good experience would perceive an improvement in their well-being. In accordance with the shopping experience quality 
theory, department store managers can develop the shopping experiences' quality by enhancing the interaction between the shops' employees and customers, providing good physical infrastructure and enhancing the shopping valence for the customers.

\section{LIMITATION AND SUGGESTION}

While providing some theoretical and practical contributions, this study also acknowledged some limitations. The first limitation is about the sample used in this study. Although the number of samples exceeded the minimum required, these samples were recruited only from department stores in Malang, in Indonesia. Hence, the findings cannot be generalized into other areas. Another limitation is about the variables used to predict subjective well-being. For this study, only the quality of the shopping experience was tested for its effect on subjective well-being.

To have a comprehensive understanding of the nature of the relationship between the shopping experience, customer satisfaction, perceived enjoyment, and subjective well-being, other researchers might replicate this model in other industry settings. In addition, to strengthen the conceptual model for predicting the individual's subjective well-being, future studies might insert other variables, such as perceived value, image, and emotion.

\section{REFERENCES}

Baron, R. M., \& Kenny, D. A. (1986). The moderator-mediator variable distinction in social psychological research: Conceptual, strategic, and statistical considerations. Journal of Personality and Social Psychology, 51(6), 1173.

Bauer, H. H., Hammerschmidt, M., \& Falk, T. (2005). Measuring the quality of e-banking portals. International Journal of Bank Marketing, 23(2), 153-175.
Bergstad, C. J., Gamble, A., Gärling, T., Hagman, O., Polk, M., Ettema, D., . . . Olsson, L. E. (2011). Subjective well-being related to satisfaction with daily travel. Transportation, 38(1), 1-15.

Chang, H.-J., Eckman, M., \& Yan, R.-N. (2011). Application of the Stimulus-Organism-Response model to the retail environment: the role of hedonic motivation in impulse buying behavior. The International Review of Retail, Distribution and Consumer Research, 21(3), 233-249. doi:10.1080/09593969.2011.578798

Chen, C.-F., \& Chen, F.-S. (2010). Experience quality, perceived value, satisfaction and behavioral intentions for heritage tourists. Tourism Management, 31(1), 29-35.

Fullerton, G. (2005). The service quality-loyalty relationship in retail services: does commitment matter? Journal of Retailing and Consumer Services, 12(2), 99-111.

Hair, J. F., Black, W. C., Babin, B. J., \& Anderson, R. E. (2010). Multivariate data analysis: A global perspective. Upper Saddle River: Pearson.

Hair, J. F., Gabriel, M., \& Patel, V. (2014). AMOS covariance-based structural equation modeling (CB-SEM): guidelines on its application as a marketing research tool. Revista Brasileira de Marketing, 13(2).

Hallowell, R. (1996). The relationships of customer satisfaction, customer loyalty, and profitability: an empirical study. International Journal of Service Industry Management, 7(4), 27-42.

Hofstede Insight. (2018). Country Comparison. Retrieved 01/05/2018, 2018,from https://www.hofstede-insights.com/countrycomparison/indonesia/

Hussein, A. S., Manna, V., \& Cohen, D. (2014). The Impact of Message Framing and Source Credibility on Breastfeeding Intention: A Social Marketing Approach. Gadjah Mada International Journal of Business, 16(2), 93109.

Hwang, Y., \& Kim, D. J. (2007). Customer selfservice systems: The effects of perceived Web quality with service contents on enjoyment, anxiety, and e-trust. Decision support systems, 43(3), 746-760.

Kim, J., Ahn, K., \& Chung, N. (2013). Examining the factors affecting perceived enjoyment and usage intention of ubiquitous tour information services: A service quality perspective. Asia Pacific Journal of Tourism Research, 18(6), 598-617.

Kline, R. B. (2005). Principles and practice of structural equation modeling: Guilford publications.

Kotler, P., \& Keller, K. L. (2012). Marketing Management. New Jersey: Pearson Education Inc. 
Lemke, F., Clark, M., \& Wilson, H. (2011). Customer experience quality: an exploration in business and consumer contexts using repertory grid technique. Journal of the Academy of Marketing Science, 39(6), 846-869.

Lowry, R., Hardy, S., Jordan, C., \& Wayman, G. (2004). Using social marketing to increase recruitment of pregnant smokers to smoking cessation service: a success story. Public Health, 118(4), 239-243.

Parasuraman, A., Zeithaml, V. A., \& Berry, L. L. (1985). A conceptual model of service quality and its implications for future research. the Journal of Marketing, 41-50.

Sirohi, N., McLaughlin, E. W., \& Wittink, D. R. (1998). A model of consumer perceptions and store loyalty intentions for a supermarket retailer. Journal of Retailing, 74(2), 223-245.

Sivadas, E., \& Baker-Prewitt, J. L. (2000). An examination of the relationship between service quality, customer satisfaction, and store loyalty. International Journal of Retail \& Distribution Management, 28(2), 73-82.

Smith, M., \& Puczkó, L. (2008). Health and wellness tourism: Routledge.

Su, L., Huang, S., \& Chen, X. (2015). Effects of service fairness and service quality on tourists' behavioral intentions and subjective well-being. Journal of Travel \& Tourism Marketing, 32(3), 290-307.

Su, L., Swanson, S. R., \& Chen, X. (2016). The effects of perceived service quality on repurchase intentions and subjective well-being of Chinese tourists: The mediating role of relationship quality. Tourism Management, 52, 82-95.

Van der Heijden, H. (2004). User acceptance of hedonic information systems. MIS quarterly, 695-704.

Vieira, V. A. (2013). Stimuli-organism-response framework: A meta-analytic review in the store environment. Journal of Business Research, 66(9), 1420-1426.

Wallin Andreassen, T., \& Lindestad, B. (1998). Customer loyalty and complex services: The impact of corporate image on quality, customer satisfaction and loyalty for customers with varying degrees of service expertise. International Journal of Service Industry Management, 9(1), 7-23.

Wang, H.-Y. (2012). Value as a medical tourism driver. Managing Service Quality: An International Journal, 22(5), 465-491.

Wang, Y. J., Doss, S. K., Guo, C., \& Li, W. (2010). An investigation of Chinese consumers' outshopping motives from a culture perspective: Implications for retail and distribution. International Journal of Retail \& Distribution Management, 38(6), 423-442.

Wilson, A., Zeithaml, V. A., Bitner, M. J., \& Gremler, D. D. (2012). Services marketing: Integrating customer focus across the firm: McGraw Hill.

Wu, H.-C., \& Ai, C.-H. (2016). Synthesizing the effects of experiential quality, excitement, equity, experiential satisfaction on experiential loyalty for the golf industry: The case of Hainan Island. Journal of Hospitality and Tourism Management, 29, 41-59.

Wu, H.-C., \& Cheng, C.-C. (2013). A hierarchical model of service quality in the airline industry. Journal of Hospitality and Tourism Management, 20, 13-22.

Wu, H.-C., \& Ko, Y. J. (2013). Assessment of service quality in the hotel industry. Journal of Quality Assurance in Hospitality \& Tourism, 14(3), 218244.

Wu, H.-C., Li, T., \& Li, M.-Y. (2016). A study of behavioral intentions, patient satisfaction, perceived value, patient trust and experiential quality for medical tourists. Journal of Quality Assurance in Hospitality \& Tourism, 17(2), 114150. 


\section{APPENDIX}

$\underline{\text { Mediating effect of Perceived Enjoyment }}$

$$
\begin{aligned}
Z & =\frac{a * b}{\sqrt{(b 2 * s a 2+a 2 * s b 2)}} \\
& =\frac{0.843 \times 0.024}{\sqrt{(0.000576 \times 0.008464)+(0.710649 \times 0.024964)}} \\
& =0.151
\end{aligned}
$$

Mediating effect of customer

$$
\begin{aligned}
Z & =\frac{a * b}{\sqrt{(b 2 * s a 2+a 2 * s b 2)}} \\
& =\frac{0.896 \times-0.133}{\sqrt{(0.017689 \times 0.0049)+(0.802816 \times 0.0475)}} \\
& =-0.608
\end{aligned}
$$

Notice: The Journal of Indonesian Economy and Business and its Boards of Editors are not responsible for any errors or flaws found in this article. The authors take full responsibility for their work. 